\title{
PSICOLOGIA E PSIQUIATRIA EM BERNARDO SANTARENO: OBSERVAR PARA NARRAR; NARRAR PARA TRATAR
}

\section{PSYCHOLOGY AND PSYCHIATRY IN BERNARDO SANTARENO: OBSERVE TO TELL; NARRATING TO TREAT}

http://dx.doi.org/10.11606/issn.2175-3180.v12i23p99-116

\section{RESUMO}

Segundo o dicionário Aurélio, a Psicologia é parte da Filosofia que trata da alma, das suas manifestações e dos fenômenos psíquicos. Já a Psiquiatria é por ele apresentada como a doutrina das doenças mentais e do respectivo tratamento. A Psicologia cuida do aspecto social e comportamental das pessoas. A Psiquiatria cuida da parte fisiológica e química envolvendo o cérebro humano. Em Nos mares do fim do mundo (1959) e O Lugre (1959), Bernardo Santareno, psicólogo, preocupa-se em descobrir as causas dos problemas sofridos pelos homens do mar, usando como principal ferramenta o conhecimento social, filosófico e comportamental. Aqui, o indivíduo é analisado no contexto em que vive, com o autor se propondo a identificar e tratar as alterações psicológicas e comportamentais por meio de técnicas conversacionais, além de ajudar a preveni-las. Por sua vez, em relação a essas mesmas obras, Santareno, psiquiatra, avalia e trata problemas psicológicos focando na parte orgânica, por meio da avaliação fisiológica e química do cérebro. Na prática, sua preocupação psiquiátrica se ocupa primeiramente em reduzir os sintomas ocasionados pelo isolamento e distanciamento social do homem no mar. Em 1957 e em 1959, Bernardo Santareno, embarcando como médico de bordo na frota bacalhoeira portuguesa (David Melgueiro, Senhora do Mar e Gil Eannes) que se dirigia todos os anos para a Terra Nova e Groenlândia, traçou pequenos quadros narrativos que realçavam o elemento humano rodeado pela mais austera natureza. Entre a linguagem poética, a reflexão e a narrativa, usou observações para narrar e narrações para tratar a trajetória marítima e de vida nas quais suas personagens se descobriam real e interiormente. Por sua vez, levando-as para a encenação, descortinou a propaganda de cunho econômico do Estado Novo, reproduzida em sua ordem social.

\section{PALAVRAS-CHAVE}

Bernardo Santareno; Psicologia e Psiquiatria; Estado Novo.

\footnotetext{
I Universidade de São Paulo, Ribeirão Preto, Brasil.

II Universidade de São Paulo, São Paulo, Brasil.
}

José Aparecido da Silva ${ }^{\mathrm{I}}$

Rosemary Conceição dos Santos ${ }^{\text {II }}$

\section{ABSTRACT}

According to the Aurélio dictionary, Psychology is part of Philosophy that deals with the soul, its manifestations and psychic phenomena. Psychiatry is presented by him as the doctrine of mental illness and its treatment. Psychology takes care of people's social and behavioral aspects. Psychiatry takes care of the physiological and chemical aspects involving the human brain. In In the seas at the end of the world (1959) and O Lugre (1959), Bernardo Santareno, a psychologist, is concerned with discovering the causes of the problems suffered by seafarers, using social, philosophical and behavioral knowledge as the main tool. Here, the individual is analyzed in the context in which he lives, with the author proposing to identify and treat psychological and behavioral changes through conversational techniques, in addition to helping to prevent them. In turn, in relation to these same works, Santareno, a psychiatrist, evaluates and treats psychological problems focusing on the organic part, through the physiological and chemical evaluation of the brain. In practice, his psychiatric concern is primarily concerned with reducing the symptoms caused by the isolation and social distance of man at sea. In 1957 and 1959, Bernardo Santareno, embarking as an on-board doctor in the Portuguese cod fleet (David Melgueiro, Senhora do Mar and Gil Eannes) who headed every year to Terra Nova and Greenland, drew up small narrative pictures that highlighted the element human surrounded by the most austere nature. Between poetic language, reflection and narrative, he used observations to narrate and narrations to deal with the maritime and life trajectory in which his characters discovered themselves real and inwardly. In turn, taking them to the stage, he unveiled the propaganda of an economic nature of the Estado Novo, reproduced in its social order.

\section{KEYWORDS}

Bernardo Santareno; Psychology and Psychiatry; New state. 


\section{INTRODUÇ̄̃O}

Em seu Discurso de Entrada à Academia Francesa, em 21 de janeiro de 1960, o célebre Jean Delay, psiquiatra e escritor, afirmou que "A psiquiatria não é só um caminho à Literatura, é a própria Literatura". O significado disso? Significa ser o médico capaz de considerar as produções literárias em diálogo com os saberes psiquiátricos e psicológicos que elas engendram, em especial, com aspectos relevantes da mente e da conduta que, nas personagens, descortinam a conduta da natureza humana.

Em Nos mares do fim do mundo (1959) ${ }^{1}$ e O lugre (1959)2 ${ }^{2}$, Bernardo Santareno, escritor e psicólogo, se preocupa em descobrir as causas dos problemas sofridos pelos homens do mar, usando como principal ferramenta o conhecimento social, filosófico e comportamental. Aqui, o indivíduo é analisado no contexto em que vive, com o autor se propondo a identificar e tratar as alterações psicológicas e comportamentais por meio de técnicas conversacionais, além de ajudar a preveni-las. Por sua vez, em relação a essas mesmas obras, Santareno, escritor e psiquiatra, avalia e trata problemas psicológicos focando na parte orgânica, por meio da avaliação fisiológica e química do cérebro. Na prática, sua preocupação psiquiátrica ocupa-se primeiramente em reduzir os sintomas ocasionados pelo isolamento e distanciamento social do homem no mar. Em ambas, entretanto, um foco em comum: o estudo do comportamento emocional.

Durante longo período, segundo Pérez-Rincón (2010), Psiquiatria e Literatura formaram um frutífero campo de encontro entre psicopatologia, antropologia, história, sociologia, filosofia e literatura. O que veio a mudar tal cenário? As frutíferas contribuições que a neurociência trouxe para tal binarismo, as quais melhoraram não só suas colocações teóricas, como também as ações terapêuticas da última. Assim, ao sarcasmo fisiologista que tratava o binômio, no início do século $X X$, como "a poesia da medicina", seguiu-se, nos princípios do século XXI, sua requalificação pelo referido campo, que passou a afirmar que suas qualidades científicas e eficientes não impediam o binômio de conservar sua participação no mundo da palavra e do simbólico, bem como, no mundo do espírito e da

\footnotetext{
${ }^{1}$ Entre parênteses, a data de publicação da obra. Neste ensaio, as citações estão sendo extraídas da edição de 1997. 2 Entre parênteses, a data de publicação da obra. Neste ensaio, as citações estão sendo extraídas da edição de 2019.
} 
noosfera, tal como buscava o reconciliador Teilhard de Chardin em contexto de religiosidade, saúde e filosofia.

Em Pérez-Rincón (2010, p. 392), tem-se que:

As diferentes síndromes psicopatológicas, as múltiplas arestas do sofrimento humano ocorrem não só na perturbação dos mais íntimos mecanismos do encéfalo, mas na vivência de um homem concreto, em um universo de significações do qual a Literatura oferece uma via áurea de acesso.

Trazendo essa afirmação para o universo santareno, em Nos mares do fim do mundo, Santareno trata, entre outros, desde distúrbios da personalidade (As peias do balanço) a retraimentos de humilhação (O bobo), sem se descuidar de nomear o desespero (O ciclone) e de evidenciar a instalação da angústia (As mulheres dos mais rijos navegadores do mundo). O que esses achados têm em comum? $\mathrm{O}$ denominador violência. A violência, ameaça ou uso real da força física contra uma pessoa ou grupo de pessoas, acarreta, aos personagens da obra, tanto ferimentos físicos quanto danos psíquicos.

Nos últimos anos, para incluírem outras possíveis consequências espirituais, psíquicas, anímicas, mentais e psicológicas, tais como ofensas, subdesenvolvimento e privação psicológica, reincidentes no final do século $\mathrm{XX}$, pesquisadores do assunto a associaram a mecanismos específicos e com a intenção de prejudicar. A relevância disso? Incluir na definição de violência outras consequências, capazes de refletir um crescente interesse de escritores em capturar a violência que resulta não necessariamente em ferimentos ou morte, mas, sim, em grande aflição a indivíduos, famílias, comunidade e sistemas gerais da sociedade em que se insere, sejam estes de saúde, trabalho e penitenciário.

Por sua vez, em O lugre (2019, p. 27), a violência pode ser identificada, entre outros, nos comportamentos dos personagens, que intencionalmente ameaçam, ou infligem, danos físicos aos outros, como, por exemplo, em "Zé Sol (Empurrando Albino com o pé.) Fora daqui!... (Com desprezo, retomando a corrida:) Peixe podre! Mulherengo!...". Neste caso, comportamentos ilegais, como, assédio moral, homicídios, assaltos, estupros e roubos vivem com outros comportamentos menos severos que, na imensidão do mar, e distante da civilização, não são alcançados pelo código penal.

Nem sempre explicitada como agressão, a violência ficcionalizada por Santareno retrata desde uma síndrome diagnóstica ou quadro 
psiquiátrico, como, por exemplo, variadas desordens de comportamentos e comportamentos agressivos, à violência numa classe mais ampla de comportamentos, como os comportamentos anti-sociais e delinquentes. Todavia, para o propósito de prevenção, é importante, ao psiquiatra e psicólogo que residem no autor, examinar as ações que potencialmente infligem danos físicos sobre uma outra pessoa ou grupos de pessoas. Por quê? Pelo fato de estas ações poderem ser reativas; isto é, em resposta a condições antecedentes, tal como ocorre numa provocação, muito comum nos navios e barcos retratados, quanto serem pró-ativas, isto é, serem consequências instrumentais ou antecipação de maiores ganhos.

Assim contextualizadas as visões psicológicas e psiquiátricas de Santareno, e sendo diversa a bibliografia que ora o pontua como psicólogo, ora como psiquiatra, cumpre esclarecer que, neste ensaio, importa-nos destacar como o enfoque dado por cada uma dessas disciplinas se apresenta nas abordagens do autor em Nos mares do fim do mundo e n'O lugre, e não em confirmá-lo atuante específico de uma especialidade ou de outra.

Segundo Pereira (2015), a psiquiatria portuguesa foi institucionalizada no período de 1884 a 1924, momento em que diversas obras sobre o assunto foram publicadas, marcando uma evidente evolução científica da disciplina. Dentre essas obras, algumas valorizavam os progressos médicos e humanitários alcançados, enquanto outras delineavam a história social e institucional do campo, apoiando-se nas ciências sociais e estudando, principalmente, o alienismo e a história das instituições psiquiátricas. Por adição, também se incluíam nesse período as publicações voltadas à evolução dos conceitos e ao estudo do processo de formação dos sintomas, oriundos de complexas interações entre os sinais cerebrais e a informação semântica. Em suma, Pereira (2015) apresenta a psiquiatria portuguesa como uma especialidade médica constituída em 1911, cujo ensino oficial deveu-se a uma campanha iniciada na década de 1880. Inicialmente muito ligada à fisiologia e à anatomopatologia, tal área vai, aos poucos, agregando uma atitude mais compreensiva, que reconhece a importância duma abordagem psicológica diversificada, seguida de acolhimento institucional e tratamento.

Por sua vez, segundo Alves (2011), na década de 1960, especialistas portugueses na área médica, entendendo que o convívio social poderia ser relevante para a recuperação do doente mental, apresentaram, em Portugal, um discurso de desospitalização desses doentes, seguido de 
inclusão social, o que diminuiria tanto a segregação quanto o isolamento em que os mesmos se encontravam. Era a Reforma Psiquiátrica que, juntamente com a Lei de Saúde Mental no . 2118, de 1963, lançava, de acordo com Siqueira-Silva (2013) e Almeida-Filho (2020), os princípios reformadores da política dos cuidados psiquiátricos no país. Santareno, vivenciando tais fatos, e observador das realidades dos pescadores de bacalhau, promoveu, em Nos mares do fim do mundo e n'O lugre, uma relação dialógica entre ambos. Suas escolhas discursivas, aqui considerando as oralidades, de modo geral, apresentadas pelos personagens, bem como suas reflexões sobre as mesmas, mostram Santareno tanto como um profissional da área psicológica quanto da psiquiátrica, tão imbricadas e interativas que estas se mostravam, então. Importante ressaltar, portanto, que, em Santareno, tanto em Nos mares do fim do mundo quanto em $O$ Lugre, os problemas de comportamentos, sejam psicológicos, sejam psiquiátricos, são sugeridos advirem da infância e da adolescência dos personagens, devido ao compartilhamento de suas influências e de suas potencialidades para romperem a ordem social.

Em face destas considerações, podemos, operacionalmente, pontuar a violência, em ambas as obras, como uma ameaça, ou uso real, da força física sobre uma pessoa, ou grupos de pessoas, equilibrada somente na ponderação do capitão do Lugre, bem como no equilíbrio do médico e das personagens, respectivamente. Medidas reativas, isto é, aquelas que são colocadas em prática após capitão, médico e líderes das narrativas empregarem-nas depois de padrões violentos de comportamentos serem estabelecidos, ainda que dispendiosas e intrusas, são frequentemente necessárias, mas dificilmente eliminarão os comportamentos violentos enraizados numa sociedade com cultura de violência crônica, em pleno Estado Novo.

Por sua vez, quando se apresentarem apenas como efeitos e impactos imediatos, principalmente pela síndrome de ativação e características ostensivas que elas causam e carregam, as medidas deixam de ser reativas quando, paliativas, ainda não forem integradas com medidas preventivas de grande alcance social e psicológico, as quais, de acordo com a literatura especializada, têm se mostrado promissoras em inibir ou adiar o início dos comportamentos-problema, incluindo a violência. Que importância tem a observação de existir tal prática na elaboração textual de Santareno? Apresentar ao leitor que os fatores de 
riscos conhecidos por gerarem comportamentos violentos podem acirrar resistências das pessoas às influências negativas. Atuando pró-ativamente, o psicólogo e psiquiatra que existe em Santareno, quando em alto mar, combate os comportamentos-problema antes que estes se estabilizem em desordens de condutas crônicas.

Literatura especializada tem analisado um conjunto de fatores de riscos individuais que predispõem à violência. Dentre estes, inclusas as características biológicas e psicológicas, identificáveis em crianças muito jovens, que podem aumentar sua vulnerabilidade às influências ambientais e sociais negativas no decorrer do seu desenvolvimento, vários estudos indicam que a variável solidão se constitui num fator de risco para a violência.

\section{NARRATIVAS E ENCENAÇÕES EM SANTARENO}

Em Nos mares do fim do mundo e n'O lugre, os personagens tripulantes dos dóris parecem ser muito mais propensos a se engajarem em severos comportamentos violentos do que os cidadãos socializados, desempenhadores de papéis sociais que contribuem para o risco da violência num nível bem mais elevado que aquele originado de estar envolvido com delinquentes. Por sua vez, essa exposição dos personagens a crimes também aumenta o risco para comportamentos violentos posteriores.

Resultados experimentais e meta-análises de diferentes estudos têm mostrado que hábitos do tipo sobreviver sozinho em ambientes hostis têm muitas consequências negativas, que vão desde a aceitação da violência como uma solução de problemas ou de conflitos interpessoais ao aumento dos sentimentos de hostilidade, passando pela desensibilização usualmente observável na redução de uma aparente apatia ou omissão das pessoas enquanto observadoras de comportamentos violentos ou violência no seu cotidiano.

Não obstante, outros efeitos apresentados por Santareno em Nos mares do fim do mundo e em $O$ lugre incluem pensamentos obsessivos, pesadelos repetitivos e perturbações do sono nas próprias personagens. Em resumo? Compreender, através do comportamento de personagens de ambas as obras que, as intervenções preventivas, mais apropriadas para eliminar, inibir ou adiar os comportamentos violentos, ou violências, que ocorrem em cada estágio do desenvolvimento humano, do mesmo modo que reconhece os fatores de risco que predispõem ou fomentam a violência, determinam que, em condições normais, a população focal, o escopo e a 
intensidade das intervenções preventivas devem ser elaboradas à luz do contexto cultural em que se encontram.

Já acerca da relação Psicologia e Literatura, Santareno foca a experiência emocional. Sobre esta, sabe-se que foram os poetas, os dramaturgos e os romancistas que fizeram as mais notáveis tentativas para descrever concretamente a experiência emocional. Para descrever o que é sentir ciúmes, remorso, medo e ansiedade, procuramos os trabalhos em que a riqueza da linguagem pareça detalhar cada aspecto das diferentes emoções. Todavia, podemos também, baseados em nossas próprias experiências pessoais, descrever e até mesmo diferenciar as várias emoções. O prazer, a vibração do amor, o medo, a raiva e a explosão do riso fazem parte do nosso cotidiano e, portanto, podemos facilmente reconhecer quando estamos felizes, irados, ansiosos ou quando alguém está triste, alegre ou encolerizado.

De fato, as emoções constituem algumas das experiências mais fundamentais do nosso eu. Sentimos cólera, medo, alegria e tristeza; sentimos culpa, orgulho e vergonha, infelicidade e satisfação, ódio e amor. Em Santareno (1997, p.17-18), tais afirmações ficam evidentes na caracterização das personagens:

O Albino ia sofrendo em silêncio e às vezes, que remédio!, chegava mesmo a emprestar aos lábios um sorriso dolorosamente pregueado. Mas no interior, lá por dentro, era uma chaga viva, um cancro que, sem tréguas, o vinha roendo: Malvados! Se lhes pudesse ser bom... Mas não podia. Enfim, uma desgraça: ele, ali no navio, era o fantoche, o bombo onde todos malhavam, o escarradoiro para onde, sem cerimónia, os outros cuspiam! Mas tantas lhe faziam que um dia...ora, ora, um dia... nada, sempre nada! Estava sozinho, não tinha ninguém por ele: como um bicho desprezível e feio...Feio! Todos lho chamavam.

Na obra, Albino, personagem principal do conto $O$ bobo, é tratado como o bobo do veleiro, sofrendo todo tipo de mazelas. O estudo de suas emoções torna-se experimentalmente possível devido à repetição de padrões de respostas reconhecíveis e determinados por um dado estímulo. Em termos psicológicos, o termo "emoção" refere-se a um estado de excitação do organismo que pode se manifestar de três maneiras diferentes: (1) experiência emocional, por exemplo, a pessoa se sente alegre; (2) comportamento emocional, por exemplo, pragueja e ataca quem a maltratar; (3) alterações fisiológicas do corpo, por exemplo, o sangue sobe à cabeça, o coração bate 
mais forte etc. Em Albino, as três se revelam combinadas e, na dificuldade de administrá-las, quando vilipendiado, o personagem, por mais que tentasse, não conseguia conter, internamente, as emoções de raiva, medo e angústia, nem, tampouco, exteriorizá-las. Até que tal sofrimento psíquico é exteriorizado: não o suportando mais, Albino esfaqueia barbaramente o cozinheiro Ricoca e o ajudante deste, Mazorro, enquanto todos dormiam.

Santareno, ao caracterizá-la, assim como a outras ao longo da obra, revela ao leitor que o estudo das emoções, na obra, torna-se experimentalmente possível devido à repetição de padrões de respostas reconhecíveis e determinadas por um dado estímulo. Em Albino, a grande variedade das experiências emocionais descritas pelo autor caracteriza quatro dimensões gerais, a saber, a intensidade do sentimento, o nível de tensão, o caráter hedonista e grau de complexidade da mesma, em um indivíduo sob pressão psicológica.

Quanto à intensidade, em Albino, as experiências emocionais vão desde uma disposição passageira pouco perceptível, até a mais violenta das manifestações: o assassinato. A cólera varia de uma leve irritação até uma fúria violenta; a alegria, de uma suave satisfação a uma exaltação empolgante, é demonstrada em lampejos de esperança que, terminadas por reticências, logo são descartadas. Logo, em relação a Albino, quanto maior a intensidade, maior a tendência para que todo o seu eu seja abrangido e esteja sob o "controle" da emoção. Quanto ao nível de tensão existente, impera ao leitor considerar o impulso para a ação desencadeada pela emoção: o cozinheiro Ricoca sugerir a vulgaridade e a luxúria da mulher do "bobo" enquanto este se encontrava ausente. Uma pessoa pode sentir-se obrigada a atacar a barreira frustradora, a fugir do objeto ameaçador, a dançar de prazer, a cantar de alegria, quando tocadas em seu ponto fraco. Estas são emoções ativas, exemplificáveis na conduta de Albino. Por sua vez, àquelas mais passivas podem não incluir esse impulso para a ação. Por exemplo? Os momentos em que Albino, mesmo triste, e sofrendo, fica sentado, sem querer movimentar-se, coagido pelo desespero de não conseguir reagir, tampouco sentir impulsos para agir.

Por sua vez, em Santareno (2019, p.20-21), temos que:

Ergue-se o pano. O lugre está fundeado. Vê-se subir do mar, puxado por grandes cordas accionadas num sistema de roldana, o penúltimo dos dóris que, na madrugada do dia em que começa o drama, tinha «arriado», quer dizer, saído para a pesca. $\mathrm{O}$ último bote da companha 
(cada dóri é tripulado por um só homem) está ainda lá fora, no oceano, em perigo mortal, lutando contra um mar de «brisa», violentíssimo. Toda a tripulação, pescadores e oficiais, está debruçada na borda do navio, comentando em alta grita as tentativas do náufrago para alcançar o lugre: brados de estímulo, invocações religiosas, gestos de desespero, corridas desordenadas; dois rezam ajoelhados. A curtos intervalos, ouve-se a sereia do navio. Vento rijo. Sempre, o grito das gaivotas. Por vezes o mar galga a amurada do veleiro, molhando os homens, que vestem todos as roupas oleadas (chapéu, casaco e saia, de cor amarela, verde ou preta) usadas pelos pescadores bacalhoeiros nas fainas da pesca e da escala (amanho do peixe); calçam botas altas de borracha negra. Nos quetes, algum bacalhau recém-pescado. Céu negro. Névoa densa. Cai o «snow». São cinco horas da tarde.

Neste excerto, Santareno apresenta ao leitor um outro nível de emoção, a emoção ativa. A diferença entre as emoções destacadas do comportamento de Albino, em sua maioria, emoções passivas, só distoantes por ocasião do assassinato do cozinheiro, fica vivamente contrastadas com as emoções ativas manifestadas pela tripulação do lugre acima, retratadas no grau máximo de excitação e de força de impulso para a ação. No caso, o que Santareno apresenta ao leitor é que as experiências emocionais variam também quanto ao prazer ou desprazer que provocam, isto é, quanto ao seu caráter hedonista. Em outras palavras, se as emoções de tristeza, vergonha e medo de Albino são desagradáveis, de outro lado, há emoções de alegria, orgulho e satisfação, consideradas agradáveis, como as demonstradas, no excerto, pela tripulação tentando animar o último pescador já sob a neve que caía. Quando ambas apresentam intersecção? Nos momentos em que, cada personagem em seu contexto, outras emoções são indiferenciadas. É o caso, por exemplo, da piedade, da admiração e da surpresa que, em algum momento, em ambos os casos são identificadas, podendo não ser claramente agradáveis ou desagradáveis.

O que o psicólogo e o psiquiatra em Bernardo Santareno estão demonstrando para seu leitor nas obras Nos mares do fim do mundo e O lugre? Estão sinalizando que as experiências emocionais variam em seu grau de complexidade. Muitas vezes o estado emocional é difícil de ser descrito e caracterizado por uma única experiência interior, de uma determinada emoção sendo esta agradável ou desagradável. Outras experiências emocionais mais simples e diretas, como, por exemplo, sentir medo diante do mar enfurecido e da neve que nele cai no mesmo momento, intercalamse com as primeiras, tecendo o intrincado sentido humano do subjetivo. 
Uma vez que todas as emoções do homem podem, praticamente, ser classificadas em seis categorias principais, começando pelas emoções básicas ou primárias e que são dirigidas para um objetivo, as emoções primárias constituem um grupo de emoções, considerado como o mais básico e mais simples e que, usualmente, está associado à busca de objetivos e com altos graus de tensão. Fazem parte deste grupo as emoções de alegria, cólera, medo, tristeza. As emoções ligadas à estimulação sensorial são as relacionadas à percepção/sensação do que é agradável ou desagradável dos objetos. O sentimento resultante? Tende a ser dirigido para o objetivo positivo ou negativo. São eles, a dor, a repugnância, o desprazer e o prazer.

Outra categoria de emoções se refere à autoestima, tais como a vergonha, o orgulho, a culpa e o remorso, além dos sentimentos de erro e fracasso. Essas emoções são essencialmente ligadas à percepção que a pessoa tem de seu próprio comportamento em relação aos padrões de comportamento, bem como ao seu nível de aspiração. Na categoria das emoções referentes a outras pessoas incluem-se aquelas que surgem principalmente diante da relação percebida da pessoa com outras, sendo os sentimentos dirigidos para elas. Estes sentimentos tornam-se muitas vezes cristalizados na forma de predisposições emocionais permanentes, ou atitudes. Estas emoções são o amor, o ciúme, a inveja e o ódio.

Constituindo-se como um drama que narra a dureza da vida dos pescadores portugueses nos mares do Norte, a serviço da frota bacalhoeira, bem como das tensões da vida a bordo dos dóris, O Lugre, além do que já mencionamos alhures, descortina ao espectador a relação quotidiana do homem com o perigo, bem como as diferentes formas pelas quais os homens reagem diante do mesmo. O confronto entre o homem e a força da natureza não só realçando as diferentes facetas dos personagens como evidenciando a existência de outros tipos de sentimentos emocionais em relação às pessoas, que, geralmente, são menos envolventes, menos ligados à busca de objetivos.

Estes sentimentos, usualmente relacionados às avaliações que se fazem de outra pessoa, por exemplo, à admiração, à simpatia, à piedade, ao desprezo e à antipatia, fazem coro com um outro grupo de emoções, o das emoções contemplativas, caracterizando-se pelo fato de a pessoa estar dirigida para a apreciação de objetos e/ou eventos. Em O Lugre, o núcleo comum desses sentimentos tem aspecto agradável e também pode exprimir 
o súbito alívio de tensão provocado pela realização do objetivo, a saber: ser capaz de enfrentar o perigo. Este último aqui representado pelo mar, a solidão e a pesca ancestral, e portanto muito mais valorativa, do bacalhau.

Refletindo sobre o aspecto histórico e denunciativo de $O$ Lugre, a saber, ser a peça um alerta de que Salazar, ao decidir não suspender a travessia do Atlântico pelos barcos portugueses durante a II Guerra Mundial, estava manipulando a sobrevivência humana para tratar de questões de segurança e de diplomacia internacional, Santareno já suscita a discussão de uma emocionalidade ligada à excitação geral e ao sentimento de bem-estar pessoal, individual, social e nacional.

Irmanadas ao grupo das disposições emocionais, a comoção social provocada pela campanha do bacalhau, em tempos em que o trigo e o bacalhau eram os produtos que mais pesavam na cadeia alimentar e na balança comercial de Portugal, é recuperada pelo autor e passa a ser descortinada como um conjunto de estados emocionais difusos e transitórios, carregado de grande conteúdo afetivo individual e social. Entretanto, a violenta repressão a que os pescadores passaram a ser submetidos, a violência que sofrem dentro dos dóris sem ter a quem recorrer, os rigores disciplinares impostos a bordo dos bacalhoeiros, as inquietações e o sofrimento daqueles personagens em condições miseráveis revelam um retrato desencantado de toda a nação. Internacionalizava-se o propósito cruel do Estado Novo.

Parecendo coexistir em pares antagônicos, seja em O Lugre, seja em Nos mares do fim do mundo, estas disposições pontuam a disposição de alegria como contrária à de depressão; a de felicidade como contrária a de tristeza; a de calma como contrária a de tensão. A disposição tendendo, então, a invadir tanto o eu quanto o ambiente. A peça, baseada nas experiências autorais e nas histórias que lhe foram contadas pelos marinheiros que conheceu enquanto médico na frota bacalhoeira portuguesa na Terra Nova, reconstrói, em seus diálogos, os comportamentos humanos, com suas diferentes reações, daqueles que eram obrigados a arriscar tudo perante a adversidade.

Quadros narrativos que realçavam o elemento humano rodeado pela mais austera natureza, Nos mares do fim do mundo e O lugre pontuam momentos de linguagem poética, reflexão e narrativa que promovem observações para se narrar ao mesmo tempo que narram trajetórias marítima e de vida para tratar personagens que se descobriam reais e 
interiormente. Na visão de Orlandi (1987, p. 139), trata-se de apresentar recortes situacionais entendidos como unidades discursivas, fragmentos correlacionando linguagens e situações. Em Santareno, considerar a articulação interpretativa, em detrimento da articulação estrutural, permite-nos considerar a importância de contextos históricos os mais diversos, em diferentes momentos do enredo, e não só quando referências lineares e casuais vão sendo narradas.

Uma vez que a narrativa simples de Nos mares do fim do mundo e a encenação de O lugre vinculam-se ao mítico e ao ideológico, a complexidade de outras se deve ao rompimento que promovem com o mítico e a ideologia real para promoção da abertura semântica, direção na qual a crítica vem se encaminhando há tempos. Privilegiando a oralidade, a narrativa simples de Santareno busca fortalecer comportamentos sociais e literários que, despretensiosos, trazem à pena o modo ingênuo, natural e primitivo de se contar histórias. Por sua vez, objetivando analisar os mitos em que repousam os valores sociais de qualquer tempo, a narrativa complexa, de imediato, se posiciona para criticar o comportamento cognitivo dos homens no decorrer da história, lançando intencionalmente, em alguns momentos, o anti-herói que, de maneira insólita, reorganiza o enredo.

Logo, o mito e a ideologia unidos em uma denunciam falsidades em outra. Entretanto, ao denunciar estas últimas, a narrativa complexa não estaria, também, recriando um novo mito, uma nova ideologia? Obviamente que sim. Simples ou complexa, a narrativa é uma construção a preencher o vazio das não-ideias, a partir de uma ideia primeira, ainda que não original. Cabe aqui a ressalva que muitos fazem sobre o não ineditismo dos enredos, a saber, que tudo que podia ser escrito já o foi, e que o novo não passa de seguidas repetições de um determinado original. Também, a ressalva de outra característica que distingue a narrativa simples da narrativa complexa: enquanto a primeira busca a primazia das personagens simples, com foco destacado em um mínimo de protagonistas, a complexa introduz estranhamentos que subvertem o simbólico, direcionando-o ao alegórico nas entrelinhas.

Tais constatações nos levam a associar, portanto, o significado e final fechado à simplicidade narrativa, ao passo que, o ambíguo, o inconsciente, o imaginário em aberto, admitindo toda a amplitude de significados, à complexidade narrativa. A utilidade destas informações? Guiar-nos desde a escolha de qual obra ler aos caminhos possíveis de uma 
análise crítica de Santareno. Porque, em análise literária, são os enredos que determinam a teoria, ou técnica, que deve ser empregada para sua melhor compreensão, e não vice-versa. Do mesmo modo, são nossos horizontes, e o que lhes falta, que ditam qual conteúdo buscar na obra que desejamos comprar.

Assim, ler o que há de olhar psiquiátrico e de olhar psicológico em Bernardo Santareno é pontuar quais caminhos o conhecimento científico desse autor lusitano aprecia percorrer, ou desconstruir, para melhor imaginar e reconstruir esse conhecimento.

\section{OBSERVAR PARA NARRAR; NARRAR PARA TRATAR}

Em Benjamin (1935; 1983), Todorov (1978; 1987) e Ricoeur (1984; 1995), tem-se, de modo geral, que as narrativas são construídas para dar sentido às experiências humanas, bem como para organizá-las temporalmente. De que forma isso ocorre? Ao narrar, o sujeito se capacita a interpretar sua vida e a criar uma significação pessoal para os eventos vivenciados. Em Lima (2013), o inconsciente é tido como uma força atuante ligada às condições que cada um tem de transformar o que ocorre em sua vida. Em Santareno, o observar para narrar trabalha o tempo todo com os conflitos internos inconscientes de cada personagem, ao passo que, identificados os sintomas, o narrar para tratar busca promover a recriação e o desenvolvimento do eu dos personagens.

Em Nos mares do fim do mundo e n'O Lugre, os diálogos e observações apresentam estórias que terceiros contam sobre uns, assim como interpretações que estes "uns" contam dos terceiros. Neles, Santareno observa tudo o que é mito ou a lenda, tragédia ou drama para, tal como ensina Dartigues (1998), depreender o que elas engendram de importante na definição pessoal que cada um dos personagens tem de si próprios. Sem narrar sobre si, o indivíduo fica impedido, ou com dificuldades, de organizar temporalmente suas experiências.

Sendo no ato de narrar como ato de fala endereçado a um outro que o vivido se constitui como experiência (Lani-Bayle, 1999), Santareno, ao narrar a experiência de vida de seus personagens, pontua como elas são escutadas e seguidas, de forma a formar um conhecimento autêntico, e válido, para todos os indivíduos de suas respectivas coletividades. $\mathrm{O}$ observar para narrar, portanto, desvelando um conjunto de narrativas 
ficcionais, elaboradas em cada caso analisado, de modo a configurar uma estrutura do universo marítimo luso em ambas as obras representado.

Em Bertrand (1998), entretanto, fica esclarecido que o processo analítico, ainda que não vise à composição narrativa, é, todo ele, constituído por narrativas que, uma vez desconstruídas, propicia a ressignificação dos acontecimentos em novas narrativas, desta vez voltadas à conscientização dos personagens sobre o que ocorre com eles. Ao fazê-lo, Santareno efetua o segundo passo aqui analiticamente proposto, a saber, o narrar para tratar.

Em Cinco Lições de Psicanálise (2003), o tratamento do trauma, da repressão, dos chistes, do erotismo e da recapitulação e transferência são apresentados por Freud como maneiras de encarar, questionar e compreender uma série de perturbações e psíquicas observáveis nas mais diferentes pessoas inseridas em sociedade. Contextualizado aos quadros narrativos visualizados por Bernardo Santareno a bordo do David Melgueiro, Senhora do Mar e Gil Eannes, esse tratamento distingue comportamentos e perfis que realçavam o elemento humano rodeado pela mais austera natureza enquanto este se dirigia, todos os anos, para a Terra Nova e Groenlândia.

Seguindo a linha freudiana, Santareno, seja Nos mares do fim do mundo, seja n'O lugre, a partir dos conteúdos que os pescadores lhe contavam, inferia suas observações clínicas, buscando identificar os núcleos patológicos que se deixavam entrever para além do sintoma nos distúrbios neuróticos. Essa perspectiva freudiana, intitulada método de associação livre, tais distúrbios eram contemplados de forma ampla, focando tanto o campo pulsional quanto a trama psíquica. De acordo com Freud (1926/2006, p. 220):

o curso da associação livre produzia um estoque abundante de ideias que podiam nos colocar na pista daquilo que o paciente havia esquecido. Com efeito, esse material não trazia à tona o que realmente fora esquecido, mas trazia tão claras e numerosas alusões a ele que, com o auxílio de certa suplementação e interpretação, o médico podia adivinhar (ou reconstruir) o material esquecido a partir dele.

Santareno, psiquiatra, com o objetivo de conduzir à consciência o material psíquico patogênico identificado, a fim de extirpar ou, ao menos, diminuir os padecimentos por eles ocasionados na tripulação com quem convivia, representa ficcionalmente, em Nos mares do fim do mundo e n'O lugre, tais morbidades e impressões. O que isto significa? Significa dizer 
que a intervenção do narrar para tratar visava ao paciente desconstruir os sentidos formulados e seguir estabelecendo novas associações e novas configurações narrativas que os reposicionassem como narradores de suas próprias estórias.

Os traumas, partes mnêmicas resultantes de momentos emocionais de grande frustração, eram tratados através das revelações que Santareno alcançava a partir dos diálogos. Gradativamente, os estados de confusão dos personagens se amenizavam quando estes expunham uma quantidade grande de experiências.

A repressão, negação e bloqueio que impediam o resgate dos traumas, era a forma dos personagens enterrarem tudo aquilo que não era bem visto socialmente. Era a forma que o personagem encontrava para manter sua personalidade protegida. Uma vez desfeita, a resistência do personagem era quebrada e, com a volta do conteúdo aflitivo à consciência, o conflito mental acabava, bem como seus sintomas.

Os chistes, ditos e piadas tendenciosas, que contêm humor e sagacidade, enquanto meios de expressão do inconsciente, serviriam como substitutos de conteúdos reprimidos. Deformando estes últimos, tiravam o foco do trauma original. Ao fazer os personagens narrá-los, Santareno alcançava uma forma de liberar determinados pensamentos inibidos pelos mesmos. Convidados a falar abertamente sobre o que quisessem, os personagens, por associação livre, exibiam o conteúdo reprimido, não sofrendo ao expor seu trauma. Por sua vez, o erotismo, quando associado a sintomas mórbidos, revelava repressões que acabavam por desencadear quadros patológicos.

Na recapitulação e transferência, o personagem, podendo adoecer quando privado de se satisfazer, bem como às suas necessidades, reprimese, fugindo da realidade enquanto regride a psique inconscientemente a níveis interiores. Com a libido se fixando aos estados evolutivos mais antigos, o personagem se vale de meios psíquicos primitivos e originários para manifestar essa necessidade. Por sua vez, nos personagens neuróticos, é comum a aparição da "transferência", sintoma em que o personagem direciona ao psiquiatra diversos sentimentos que misturam fantasias, hostilidade e também afeto.

Em contextos de psicologia e psiquiatria, essas cinco lições configuram, portanto, um encontro entre o sujeito da aprendizagem e a realidade social. Partindo da relação entre aprendizagem e experiência, a 
saber um dos núcleos da obra do filósofo da educação John Dewey (18591952), entendemos que são fundamentais para, aqui contextualizadas, atestarem a capacidade de Santareno em refletir sobre o vivido, reconstruindo-o ficcionalmente. Por adição, constituindo-se como elemento fundamental dos métodos observacional e narrativo, atuam, também, como técnicas de associação livre que convidam as personagens (tidas como pacientes) a expressarem tudo aquilo que lhes passe pela mente visando a aprender com a experiência do ato de pensar.

Em Nos mares do fim do mundo e n'O lugre, a aplicação desses conhecimentos psicológicos e psicanalíticos podem atingir o sentido proposto por Dewey, no qual os personagens (pacientes) pudessem experimentar o sentido social de suas ações.

\section{CONCLUSÃO}

Em resumo, as emoções, em geral, provocadas que são, constantemente, por situações psicológicas específicas, motivaram o psicólogo e psiquiatra que coexistiam em Santareno a mostrar ao leitor, em Nos mares do fim do mundo e em O Lugre, que as mesmas podem, certamente, ser úteis ou prejudiciais ao comportamento adaptativo do organismo, mas que estes efeitos dependem, por certo, de sua intensidade e das condições ambientais em que elas são despertadas.

No contexto do distanciamento espacial e da solidão a que as personagens dessas obras estão inseridas, a emoção é uma força poderosa dos problemas humanos; é o "sal da vida" e, de certa forma, um registro de preservação cultural de uma prática antiga portuguesa, a pesca do bacalhau.

A mesma que, levada para a encenação, descortinou ao mundo a propaganda de cunho econômico do Estado Novo, reproduzida em sua ordem social: ao manter no mar a frota do bacalhau durante a II Guerra Mundial, alegando ser este o "pão" dos lusitanos, Salazar impôs a morte a dezenas de pescadores sob o bombardeio de submarinos nazistas, numa opressão silenciada e sem fim de trabalhadores que ali foram obrigados a sobreviver em condições miseráveis. 


\section{REFERÊNCIAS}

ALMEIDA FILHO, Antonio José de. et al. Trajetória histórica da reforma psiquiátrica em Portugal e no Brasil. Revista de Enfermagem Referência. Série IV - n. ${ }^{\circ} 4$ - jan./fev./mar. 2015. p.117-125. Disponível em < http://dx.doi.org/10.12707/RIV14074 > Acesso em 14 dez 2020.

ALVES, F. A. Doença mental nem sempre é doença. Racionalidades leigas sobre saúde e doença mental: Um estudo no norte de Portugal. Porto, Portugal: Afrontamento, 2011.

BENJAMIN, W. Le narrateur. Réflexions sur l'oeuvre de Nicolas Leskov (1935). In Essais 2 (M. de Gandillac, Trans.). Paris: Denoël, 1983.

BERTRAND, M. Valeur et limites du narratif en psychanalyse. In M. Bertrand (Ed.), Psychanalyse et récit. Stratégies narratives et processus thérapeutiques. Besançon, France: Presses Universitaires Franc-Contoises, 1998, p. 9-19.

DARTIGUES, A. Paul Ricoeur e a questão de identidade narrativa. In CESAR, C. M. (Ed.). Paul Ricoeur. Ensaios. São Paulo: Paulus, 1998, p. 7-25.

DELAY, Jean. "Discours de réception de Jean Delay". Disponível em < http://academie-francaise.fr/discours-de-reception-de-jean-delay $>$ Acesso em 15 outubro 2020.

FREUD, S. Cinco lições de psicanálise. Rio de Janeiro: Imago, 2003.

FREUD, S. A questão da análise leiga: conversações com uma pessoa imparcial (1926). In Obras psicológicas completas de Sigmund Freud: edição standard brasileira. Vol. 20. Rio de Janeiro: Imago, 2006.

LANI-BAYLE, M. L'enfant et son histoire. Vers une clinique narrative. Ramonville Saint-Agne, France: Erès, 1999.

LIMA, Luiz Tenório Oliveira. Freud. São Paulo: Publifolha, 2013.

ORLANDI, Eni Pulccinelli. O sentido dominante: a literalidade como produto da história. In: A linguagem e seu funcionamento. Campinas: Pontes, 1987, p. 135-148.

PEREIRA, José Manuel Morgado. A Psiquiatria em Portugal: Protagonistas e história conceptual (1884-1924). Tese de doutoramento. Faculdade de Letras da Universidade de Coimbra. Coimbra: Setembro, 2015. 
PÉREZ-RINCÓN, Héctor. Psiquiatria e Literatura. Rev. Latinoam. Psicopat. Fund., São Paulo, v. 13, n. 3, p. 391-394, setembro 2010.

RICOEUR, P. Tempo e narrativa (1984), vol. 2. Campinas, SP: Papirus, 1995.

SANTARENO, Bernardo. Nos mares do fim do mundo: doze meses com os pescadores bacalhoeiros portugueses, por bancos da Terra Nova e da Groenlandia. Lisboa: Expo 98, 1997.

SANTARENO, Bernardo. O lugre: peça em 6 quadros. Silveira, Lisboa: EPrimatur. 2019.

SILVA, J. A. Psicologia E Comportamentos. Ribeirão Preto: Canavaci, 2003.

SIQUEIRA-SILVA, R. et al. Portugal e Brasil no cenário da saúde mental. Fractal: Revista de Psicologia, 25(3), 2013, p. 475-496.

TODOROV, T. La notion de littérature et autres essais. Paris: Éditions du Seuil, 1987.

Recebido em 19 de novembro de 2020

Aprovado em 4 de dezembro de 2020

Licença: (ㄷ) (i) ():

José Aparecido da Silva

Mestre e Doutor em Psicologia pelo Instituto de Psicologia da Universidade de São Paulo e Pósdoutorado em Percepção e Psicofísica pela Universidade da Califórnia, Santa Bárbara, USA, é Professor Titular Aposentado do Departamento de Psicologia da FFCLRP-USP. Na Universidade de Coimbra é Co-Coordenador do Mestrado em Psicologia Experimental e, na Universidade Nacional de Tucumán (Argentina), é co-coordenador do Centro Associado de Pós-graduação apoiado pela CAPES (Brasil) e pela SPU (Argentina). Em 2017 criou e é o coordenador do Curso de MBA da USP Comportamento nas Organizações. Ministra no PECE USP/POLI as disciplinas Inteligência Emocional e O Processo de Liderança.

Contato: jadsilva@ffclrp.usp.br

(D): https://orcid.org/ 0000-0002-1852-369X

Rosemary Conceição dos Santos

Pós-Doutorado em Estudos Comparados de Literaturas de Língua Portuguesa pela Universidade de São Paulo. Pós-Doutorado em Literaturas de Língua Portuguesa pela Pontifícia Universidade Católica. Pós-Doutorado em Letras Clássicas e Vernáculas pela Universidade de São Paulo. PósDoutorado em Cognição, Leitura e Literatura pela Universidade de São Paulo (2009). Doutorado em Literatura Portuguesa pela Universidade de São Paulo. Mestrado em Estudos Literários pela Universidade Estadual Paulista "Júlio de Mesquita Filho".

Contato: cienciausp@usp.br

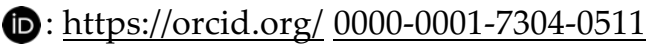

